\title{
Discussion on E-books and Library Borrowing Service
}

\author{
Weiguo Xie* \\ Library of Zhongyuan Institute of Technology, China \\ *Corresponding author: Weiguo Xie, 2496828821@qq.com
}

\begin{abstract}
With the vigorous development of network information technology, e-book borrowing service came into being and showed a vigorous development trend. Therefore, in order to strengthen the service function, the library needs to gradually improve the e-book borrowing service, so as to provide readers with high-quality service content, so that the library can give full play to its function of disseminating scientific and cultural knowledge. Therefore, in this article research, we first discuss the main reading methods of e-books, then investigate the current reading situation of e-books and traditional paper books in the library, and then put forward corresponding development strategies to effectively promote the rapid development of the library and strengthen the level of e-book borrowing service.
\end{abstract}

Keywords: E-books; Library; Borrowing service

Publication date: July 2021; Online publication: July 31, 2021

\section{Introduction}

In the construction and development of our society, network information technology has been widely used and practiced, which has a positive impact on the development and construction of various fields of society. With the continuous development of network information technology, e-books came into being. It can use the Internet as the carrier to spread knowledge, so that readers can read through network channels, which effectively strengthens the convenience of the reading process. At the same time, it is also a more convenient way for readers to obtain books, and give full play to the dissemination function of scientific and cultural knowledge of books. Since the electronic books came into being, the service mode of the library has changed correspondingly. E-book service for the readers has become an important way of service. Therefore, in order to further strengthen the service level of the library, make it better dissemination of scientific and cultural knowledge, it is necessary to strengthen the library borrowing service discussion and research, so as to constantly improve the service mode of the library, so that the library can play a better role in the current network information age.

\section{Main reading methods of e-books}

With the wide application of Internet technology, e-books have become a new way of reading, and have been favored and recognized by the majority of readers. E-books have good convenience in the reading stage, so they have developed rapidly. In the development, the main reading methods of e-books are divided into the following:

\section{(1) Online reading}

Online reading is not only the main form of e-book communication, but also an important way for readers to read e-books. It is mainly that readers search e-books through browsers and then read on the Internet. For example: Readers can log in to the e-book website through computer devices or mobile intelligent 
terminals, and then read online for free or paid ${ }^{[1]}$. At present, during the development of e-books, there are relatively few kinds of free e-books that can be provided by various e-book websites. At the same time, the publishing age of various books is relatively long. Paid reading can obtain richer e-book content. Therefore, online paid reading has gradually developed into a mainstream e-book reading method, and has wide recognition in the scope of the public.

\section{(2) Offline download reading}

Offline download reading is one of the main reading methods of e-books. It refers to that readers use the corresponding network reading software to download the paid or free books on the website offline, and then generate the file format for readers to read, so that they can read offline on the readers' personal computer or mobile intelligent terminal. At present, the way of offline download reading is also common. Readers can download their favorite e-books through software and use their spare time to read, which has a positive impact on the development of e-books.

\section{(3) Reading on CD}

Reading with CD is also an important way of reading e-books. Usually, readers can put the CD into personal computers or other e-reading devices, so that they can read the e-book information in the $\mathrm{CD}$, and then carry out the reading process. In essence, reading through CD is also a way of offline reading. Generally, some e-book supply websites will consider the download rate of e-books, so they will provide readers with paid book $\mathrm{CD}$ to enable readers to read offline through $\mathrm{CD}^{[2]}$. In addition, some publishing houses in China will also provide electronic $\mathrm{CD}$ during the book sale, or issue $\mathrm{CD}$ versions of books to help readers improve the convenience of reading.

\section{Investigation on the reading status of e-books and traditional paper books in library}

In this paper, a random survey was conducted among 100 readers in the form of questionnaire survey to understand the current reading situation of e-books and traditional paper books in the library and readers' preferences for the above two reading methods. The survey results are as follows:

\subsection{Comparison of reading convenience survey}

The following Table 1. shows the survey and statistics on the reading convenience of e-books and paper books. According to the following statistical table, 79 respondents believe that e-books are relatively convenient to read, accounting for $79 \%$. This part of readers believe that e-books are far more convenient than paper books in the reading stage, At the same time, the excellent attributes of e-books are not comparable to those of paper books, such as: Paper books have the function of text retrieval, and can also be consulted in the catalogue, so it is more convenient to find the contents of the whole book. In addition, at the stage of reading e-books, readers can freely use the functions of e-book labels, lines, annotations and highlights. The text in e-books can also be enlarged and reduced with the reader's reading appropriateness, and these advantages are not provided by traditional books. Moreover, e-books have good convenience in the carrying stage. Often, an e-book with about 1 million words occupies only about $10 \mathrm{M}$ of storage space, while it exceeds $400 \mathrm{~g}$ if carrying paper books. Therefore, e-books have stronger convenience than traditional paper books.

Thirteen people think it is convenient to read paper books, accounting for $13 \%$. This part of readers think that although the electronic reading equipment is exquisite and easy to carry, the electronic equipment needs to be turned on or off, and will also be limited by hardware such as power supply. During the reading process, it will be affected by the surrounding light conditions, such as: It's almost impossible to read directly in sunlight. However, if you choose traditional paper books, you can browse books from any angle anytime, anywhere, and will not be limited by the power supply. As for the reading of a book, paper books 
are relatively more convenient.

The number of people who hold a neutral attitude towards the two is 8 , accounting for $8 \%$. This part of readers believe that traditional paper books and e-reading have their own advantages, so they will choose e-reading or paper reading according to their own preferences and specific reading environment.

Table 1. Survey and statistics of reading convenience of e-books and paper books

\begin{tabular}{cccc}
\hline & E-book is convenient & Paper book is convenient & Each has its own advantages \\
\hline Number of people & 79 people & 13 people & 8 people \\
Proportion & $79 \%$ & $13 \%$ & $8 \%$ \\
\hline
\end{tabular}

\subsection{Comparison of reading comfort survey}

Table 2. below is a statistical table for the reading comfort of electronic books and paper books. It surveys 100 readers on the reading comfort of electronic books and paper books respectively and makes statistical table 2 below. Among them, 75 people thought that e-reading was more comfortable, accounting for $75 \%$. This part of readers thought that the reading method of e-books had good convenience. At the same time, e-books only need to move a finger to complete the page turning process during reading, while traditional paper books need to turn the pages manually one by one. At the same time, small and exquisite handheld electronic devices are more comfortable in the reading stage, so the comfort of choosing e-reading mode is obviously better than traditional paper books.

The number of people who think that the reading method of paper books is more comfortable is 34 , accounting for $34 \%$. This part of readers think that there are great differences between paper book reading and e-book reading. It needs to be applied to e-reading equipment and related reading software, and the essence of this reading method is to see the content display on the screen, which belongs to a kind of "screen reading," In the reading stage, the screen will reflect, flicker and shake, causing discomfort to people's eyes. If reading for a long time, it is prone to visual fatigue, while the selection of traditional paper books will not produce the above situation. Therefore, it believes that traditional paper books have better comfort.

The number of people who think that the reading comfort of e-books is similar to that of paper books is 11 , accounting for $11 \%$. This part of readers think that the reading comfort of choosing paper books and ebooks is similar. Both of them need readers' attention and eyes to read the contents of books in the reading stage. Reading for a long time will produce problems such as visual fatigue and shoulder and neck pain. Therefore, appropriate activities and relaxation in the reading stage can improve the comfort of the reading stage.

Table 2. Survey and statistics of reading convenient of e-books and paper books

\begin{tabular}{cccc}
\hline & $\begin{array}{c}\text { E-books are comfortable to } \\
\text { read }\end{array}$ & $\begin{array}{c}\text { Paper books are comfortable to } \\
\text { read }\end{array}$ & The two are similar \\
\hline $\begin{array}{c}\text { Number of people } \\
\text { Proportion }\end{array}$ & 55 people & 34 people & 11 people \\
\hline
\end{tabular}

\section{Library e-book borrowing service strategy}

\subsection{Changing the concept of book service}

In the daily operation and development of the library, book service is an important content. Whether to provide readers with high-quality book service also determines the readers' reading experience and satisfaction. Therefore, in order to effectively promote the development and innovation of library e-book service, the primary task is to change the book service concept, so as to gradually open up a new service form, so that readers can enjoy high-quality e-book borrowing services in the library ${ }^{[3]}$. First of all, the 
library needs to pay attention to innovation, focus on reader oriented, change the service form, make full use of network information technology and various intelligent terminals to provide e-book borrowing services for readers, so that readers can obtain more abundant e-book resources.

\subsection{Provide personalized e-book borrowing service}

Providing personalized e-book borrowing services for readers is also an important measure to improve readers' satisfaction. At the same time, it is also conducive to the library to give full play to its function of disseminating scientific and cultural knowledge, make the social reading atmosphere stronger, and help strengthen the comprehensive quality of our people ${ }^{[4]}$. For example: The book retrieval function can be set up in the library portal. Readers can carry out book retrieval according to the e-books they need to obtain, improve the convenience for readers to obtain the target books through retrieval, and open some free ebook download services to continuously shorten the distance between the library and readers and enhance the stickiness of readers. In addition, it can also provide customized e-book borrowing services for readers to meet the personalized reading needs of different types of readers, so as to effectively promote the development and innovation of Library e-book borrowing services.

\subsection{Improve e-book resources}

Improving e-book resources is an important measure. Through this measure, different types of readers can be guaranteed to obtain their favorite e-book resources. Therefore, more energy needs to be invested in this work to strengthen the service function of the library ${ }^{[5]}$. For example: The library can build an e-book resource information database, and then strive to strengthen the integration of various e-book resources, so as to enrich the library's e-book inventory, so that readers can enjoy comprehensive and comprehensive book borrowing services in the library. In this process, the staff of all posts in the library need to strengthen the study of network information technology, understand and study how to correctly carry out e-book borrowing service, so as to effectively improve the service function of the library.

\section{Conclusion}

To sum up, e-book service plays a vital role in the daily operation and development of public libraries. Whether to provide readers with high-quality e-book borrowing service also determines the operation level of the library. Therefore, it is necessary to scientifically design and plan all links of the work to comprehensively promote the improvement of the e-book borrowing service level of the library.

\section{Disclosure statement}

The author declares no conflict of interest.

\section{References}

[1] Liu HZ, 2019, A Study of Electronic Books and Library Borrowing Service. Archives, 009 (009): 42.

[2] Liu L, Hu XW, Luo YL, 2019, Research on Library E-book Borrowing Policy Based on Stakeholder Needs. Library, 293 (02): 108-115.

[3] Huang XT, Li YX, Xue WL, 2011, Research on the Application of E-reader in Library Borrowing Services, Library Science Research \& Work, 01 (1): 22-22.

[4] Zheng YY, Yi TS, 2006, Electronic Books and Library Borrowing Service. Journal of Library and Information Sciences in Agriculture, 18 (011): 65-68.

[5] Xu WH, Chen LS, 2014, Service and Application of Electronic Borrowing System in Library. Lantai world, 32 (No. 454): 119-120. 